\title{
Rastreamento do câncer de colo uterino em índias do Parque Indígena do Xingu, Brasil central
}

\author{
Wladimir Correa Taborda, ${ }^{1}$ Selma Carneiro Ferreira, ${ }^{1}$ Douglas \\ Rodrigues, ${ }^{1}$ João Norberto Stávale ${ }^{2}$ e Roberto Geraldo Baruzzi ${ }^{1}$
}

\begin{abstract}
RESUMO Embora a literatura apresente dados preocupantes sobre a incidência do câncer de colo uterino entre povos indígenas, no Brasil são muito escassas as informações a respeito da ocorrência do câncer nessa população. Assim, o objetivo do presente estudo descritivo foi analisar a prevalência de câncer do colo uterino e de infecções cérvico-vaginais em 423 mulheres indias, habitantes do Parque Indígena do Xingu, Estado do Mato Grosso, com vida sexual ativa presente ou pregressa. Os dados foram coletados entre 1989 e 1996. Foram realizados exames clínico e ginecológico previamente à obtenção de esfregaço da cérvice uterina e estudo da citologia oncológica, complementados por colposcopia e biópsia nos casos positivos. Os resultados demonstraram que 1\% das mulheres apresentava carcinoma invasivo e 3\% apresentavam lesões prémalignas. Além disso, evidenciou-se que $84 \%$ das mulheres apresentavam atipias celulares de natureza inflamatória, decorrentes de infecções genitais sexualmente transmitidas. Estes achados estão de acordo com a literatura internacional quanto à elevada prevalência dessas doenças em populações nativas e indicam a importância de serem estendidos aos povos indígenas do Brasil os programas de controle, tanto das doenças sexualmente transmissíveis, como de detecção e tratamento precoces do câncer do colo do útero.
\end{abstract}

O câncer de colo uterino e o câncer de mama representam, entre as neoplasias malignas, as principais causas de óbito na população feminina de 15 anos ou mais em nosso país $(1,2)$. O início da atividade sexual em idade

\footnotetext{
Universidade Federal de São Paulo, Escola Paulista de Medicina, Unidade de Saúde e Meio Ambiente, Departamento de Medicina Preventiva. Correspondência e pedidos de separatas devem ser enviados a Roberto G. Baruzzi no seguinte endereço: Universidade Federal de São Paulo, Escola Paulista de Medicina, Rua Botucatu 740, CEP 04023-062, São Paulo, SP, Brasil. Telefone: +55-11575-7161/571-6934; fax: +55-11-549-5159; e-mail: baruzzi@medprev.epm.br

2 Universidade Federal de São Paulo, Escola Paulista de Medicina, Unidade de Saúde e Meio Ambiente, Departamento de Anatomia Patológica, São Paulo, SP, Brasil.
}

precoce, o maior número de parceiros sexuais e a multiparidade são considerados fatores de risco preponderantes para o câncer do colo uterino $(3,4)$. Estes fatores estão presentes, de maneira geral, nos povos indígenas da América. A literatura apresenta dados preocupantes sobre a incidência do câncer do colo uterino nesses povos (5-8).

A ocorrência de doenças sexualmente transmissíveis (DST), particularmente de infecções pelo papilomavírus humano (HPV), representa um importante fator de risco adicional de carcinogênese cervical. Diversos estudos epidemiológicos têm confirmado que o HPV (especificamente os subti- pos 16 e 18) determina uma importante progressão das lesões pré-clínicas para as formas invasivas, admitindo-se que a neoplasia intra-epitelial cervical II ou III possa ocorrer até 2 anos após a infecção primária por esse vírus (6, 9-14).

Young e Choi (7) apontam prevalência de $14 \%$ de neoplasia cervical em 115 casos de câncer ocorridos em habitantes de reservas indígenas de Manitoba, Canadá, de 1970 a 1979. Storm et al. (15) demonstraram que, na Groenlândia, a incidência foi 3,2 vezes maior em mulheres nativas quando comparadas a mulheres dinamarquesas. Elevados índices de DST, início precoce da atividade sexual e multiplicidade 
de parceiros sexuais foram apontados como os principais fatores de risco responsáveis pela elevada ocorrência de neoplasia cervical na população da Groenlândia.

Segundo dados oficiais, a população indígena no Brasil é de 325000 índios, sendo muito escassos os dados a respeito da ocorrência do câncer do colo uterino nessa população. Um inquérito realizado em 1989, com 89 mulheres da tribo Parakanã, encontrou uma prevalência de $3 \%$ de lesões cervicais prémalignas (16). Assim, o presente inquérito teve como objetivo estudar a ocorrência do câncer de colo uterino em mulheres do Parque Indígena do Xingu (PIX), Estado do Mato Grosso (Brasil Central). A prevalência de DST e de alterações citológicas da cérvice uterina foram avaliadas, visando a instituir um programa de prevenção do câncer do colo do útero naquela população.

\section{MATERIAIS E MÉTODOS}

O Parque Indígena do Xingu (PIX) está localizado no norte do Estado do Mato Grosso, entre $9^{\circ} 50^{\prime}$ e $13^{\circ}$ de latitude Sul e entre $52^{\circ} 30^{\prime}$ e $54^{\circ}$ de longitude Oeste, numa área de $32000 \mathrm{~km}^{2}$ que se estende ao longo dos formadores do rio Xingu (afluente da margem direita do rio Amazonas), ao sul, até a cachoeira de Von Martius, ao norte, nos limites com o Estado do Pará. É uma área de transição entre o cerrado do Brasil central e a floresta amazônica. A região apresenta duas estações climáticas bem definidas: chuvosa, de outubro a março, e seca, de abril a setembro.

A população do PIX é de 3908 índios (49\% do sexo feminino), pertencentes a quatro diferentes troncos lingüísticos e distribuídos por 26 aldeias e quatro postos indígenas. A Escola Paulista de Medicina (EPM) desenvolve, desde 1965, um programa de saúde em parceria com a Fundação Nacional do Índio (FUNAI) para atender as 17 tribos que lá habitam. Existem quatro postos permanentes de assistência no Parque. Esses postos contam com pessoal de saúde de nível médio e superior, sendo as aldeias periodicamente visitadas por equipes de saúde que procedem à vacinação e ao atendimento clínico. O Hospital São Paulo, hospital escola da EPM, oferece a retaguarda hospitalar para os casos que necessitam de atendimento especializado. Desde o início da década de 80 , tem crescido o contato das tribos com comunidades não indígenas, em função da maior facilidade de acesso à região e da abertura de fazendas e garimpos em suas cercanias, levando a um maior risco de DST.

No inquérito foram incluídas 20 aldeias. ${ }^{3}$ Os postos foram excluídos por terem função administrativa e população flutuante; também foram excluídas seis aldeias, com uma população estimada em 500 índios. A exclusão se deveu ao número reduzido de habitantes por aldeia e à sua localização em áreas de difícil acesso.

A população-alvo foi definida como as mulheres que tinham ou haviam tido vida sexual ativa. A informação a respeito de atividade sexual foi obtida através de auto-relato, estimulado por pergunta específica, antes da coleta do esfregaço cérvico-vaginal. Todas as mulheres, assim como toda a população, tinham fichas médicas. Primeiramente, foram incluídas no estudo 392 mulheres com 15 anos ou mais, correspondendo a $47 \%$ das mulheres pertencentes a este grupo etário nas 20 aldeias que participaram do estudo; as restantes nesse grupo etário não se encontravam na aldeia por ocasião do exame, muitas em trabalho na roça, ou se recusaram a participar. Adicionalmente, foram incluídas mais 31 adolescentes menores de 15 anos de idade, perfazendo um total de 423 mulheres, que, por sua vez, cor-

\footnotetext{
3 As aldeias incluídas no estudo (e os grupos étnicos a que pertencem) são as seguintes: Aweti (Aweti); Cachoeira (Metuktire); Capivara (Kayabí); Capoto (Metuktire); Cururu (Kayabi); Kalapalo (Kalapalo); Kamayurá (Kamayurá): Kuikuru (Kuikuru); Moingu (Txikão); Matipu (Matipu); Mehináku (Mehináku); Morená (Kamayurá); Nahukwá (Nahukwá); Panará (Panará); Ricô (Suyá); Sobradinho (Kayabí); Tuba-Tuba (Juruna); Tuiararé (Kayabí); Waurá (Waurá); Yawalapiti (Yawalapiti).
}

respondiam a $51 \%$ da população alvo das 20 aldeias.

As mulheres compareceram por demanda espontânea, após ampla explicação sobre a importância do câncer do colo uterino, os exames que seriam realizados e as medidas preventivas a serem adotadas. A identificação das mulheres foi feita a partir das fichas médicas individuais utilizadas no trabalho de campo, introduzidas a partir do final da década de 1960, quando teve início o programa da EPM no PIX. Nas fichas estão registradas ocorrências clínicas e dados da história obstétrica pregressa. O exame ginecológico e coleta de material foram feitos nas aldeias, com auxílio de intérpretes para a obtenção de informações, quando necessário.

O exame ginecológico, realizado por médico e enfermeira, consistiu na inspeção e palpação das mamas e axilas, palpação abdominal, exame especular com coleta de material para citologia e toque vaginal bimanual. A coleta de material foi padronizada de forma a discriminar três regiões específicas: fundo de saco vaginal, junção escamocolunar (exocérvice) e canal endocervical (endocérvice). Após a coleta tríplice em lâminas devidamente identificadas, os esfregaços foram imediatamente fixados em álcool absoluto $\left(98^{\circ}\right)$ e acondicionados de forma segura. As lâminas foram coradas em período não superior a 15 dias após a coleta, pelo método de Papanicolaou (17) e submetidas a exame citopatológico no departamento de patologia da EPM. Além da pesquisa de alterações citológicas, procurou-se identificar, sempre que possível, a flora vaginal presente no material obtido.

\section{RESULTADOS}

Em 423 mulheres examinadas, observou-se que $84 \%$ apresentavam atipias celulares inflamatórias; $3 \%$ apresentavam anormalidades citológicas pré-malignas (neoplasia intra-epitelial tipo I, II ou III); e $1 \%$ apresentava carcinoma invasor de colo uterino (tabela 1). A distribuição dos diagnósticos citológicos 
TABELA 1. Prevalência de alterações citopatológicas da cérvice uterina em 423 mulheres índias, Parque Indígena do Xingu (MT), Brasil, 1989 a 1996

\begin{tabular}{lrr}
\hline \multicolumn{1}{c}{ Classificação descritiva } & No. & $\%$ \\
\hline Citologia normal & 50 & 12 \\
$\begin{array}{l}\text { Atipias inflamatórias } \\
\text { Displasia leve/neoplasia } \\
\text { intra-epitelial I }\end{array}$ & 356 & 84 \\
$\begin{array}{l}\text { Displasia moderada/neoplasia } \\
\quad \text { intra-epitelial II }\end{array}$ & 5 & 1 \\
$\begin{array}{l}\text { Displasia grave, carcinoma in } \\
\quad \text { situ/neoplasia intra-epitelial III }\end{array}$ & 4 & 1 \\
$\begin{array}{l}\text { Carcinoma invasivo } \\
\quad \text { Total }\end{array}$ & 3 & 1 \\
& 5 & 1 \\
& 423 & 100 \\
\hline
\end{tabular}

nas diferentes faixas etárias da população de estudo é apresentada na tabela 2. Ressalta-se a ocorrência de neoplasia intra-epitelial (NIC) I (três casos), NIC II (um caso), NIC III (um caso) e carcinoma invasivo (um caso) em mulheres na faixa dos 20 aos 29 anos. Além disso, verificou-se a ocorrência de alterações citológicas em todas as faixas etárias, com exceção do grupo etário menor ou inferior a 20 anos.

Em relação aos 356 casos de atipias inflamatórias, não foi possível a identificação do agente etiológico em 66\% dos esfregaços. A etiologia infecciosa mais comumente identificada foi a vaginose bacteriana, seguida de Trichomonas vaginalis. Cumpre ressaltar que $2 \%$ das mulheres apresentaram alterações citológicas sugestivas de $\mathrm{HPV}$ (tabela 3).

\section{DISCUSSÃO}

O carcinoma do colo uterino é apontado como responsável por $23 \%$ das neoplasias malignas em mulheres no Brasil $(1,2)$ e constitui um problema prioritário de saúde pública em diversos países da América Latina e do Caribe $(6,18)$. Início precoce da atividade sexual, primiparidade precoce, associada à multiparidade, e multiplicidade de parceiros, além da presença de DST, figuram entre os principais fatores de risco identificados por diversos estudos epidemiológicos (3, 4, 6, 18, 19). A esses fatores de risco somam-se, como agravantes, a precariedade de condições socioeconômicas e as dificuldades de acesso aos serviços de saúde. Nas populações indígenas brasileiras, além dos fatores de risco acima apontados, são inexistentes os programas específicos de rastreamento e diagnóstico, o que dificulta o tratamento na fase pré-clínica da doença.

Admite-se que o câncer de colo uterino se inicia em nível celular e progride para os vários estágios de neoplasia intra-epitelial, para finalmente penetrar através da membrana basal e transformar-se em carcinoma microinvasor (14). Com o passar do tempo, as manifestações clínicas, especialmente sangramento genital, tornam-se evidentes. Embora nem todas as lesões evoluam para a invasão, algumas obviamente o fazem. Além disso, por ocasião do diagnóstico, quanto mais avançado o grau de NIC, tanto maior

TABELA 2. Distribuição do diagnóstico citopatológico da cérvice uterina segundo a faixa etária em 20 aldeias do Parque Indígena do Xingu (MT), Brasil, 1989 a 1996

\begin{tabular}{|c|c|c|c|c|c|c|c|}
\hline \multirow[b]{2}{*}{ Idade } & \multirow[b]{2}{*}{ Normal } & \multirow[b]{2}{*}{ Atipia } & \multicolumn{3}{|c|}{ Neoplasia intra-epitelial } & \multirow{2}{*}{$\begin{array}{c}\text { Carcinoma } \\
\text { invasivo }\end{array}$} & \multirow[b]{2}{*}{ Tota } \\
\hline & & & I & II & III & & \\
\hline$<15$ anos & 6 & 25 & - & - & - & - & 31 \\
\hline $15-19$ & 13 & 63 & - & - & - & - & 76 \\
\hline $20-24$ & 6 & 59 & 1 & - & 1 & - & 67 \\
\hline $25-29$ & 9 & 68 & 2 & 1 & - & 1 & 81 \\
\hline $30-34$ & 4 & 44 & - & 1 & - & - & 49 \\
\hline $35-39$ & 3 & 30 & - & 1 & 1 & 1 & 36 \\
\hline $40-44$ & 4 & 27 & 2 & - & 1 & - & 34 \\
\hline $45-49$ & 3 & 16 & - & - & - & 2 & 21 \\
\hline $50 e+$ & 2 & 24 & - & 1 & - & 1 & 28 \\
\hline Total & 50 & 356 & 5 & 4 & 3 & 5 & 423 \\
\hline
\end{tabular}

TABELA 3. Agentes etiológicos identificados em 356 mulheres índias com atipia inflamatória cérvico-vaginal, Parque Indígena do Xingu (MT), Brasil, 1989 a 1996

\begin{tabular}{lrr}
\hline \multicolumn{1}{c}{ Agente etiológico } & No. & $\%$ \\
\hline Indeterminado & 234 & 66 \\
Vaginose bacteriana & 51 & 14 \\
Trichomonas vaginalis & 48 & 13 \\
Chlamydia trachomatis & 08 & 2 \\
HPV & 06 & 2 \\
Candida albicans & 03 & 1 \\
Flora mista & 06 & 1 \\
Total & 356 & 100 \\
\hline
\end{tabular}

o risco de desenvolvimento de lesões invasivas, admitindo-se que o tempo necessário para a progressão da NIC pode variar de 2 a 20 anos, na dependência dos fatores de risco envolvidos e da presença de infecções genitais pelo HPV $(10,12)$.

$\mathrm{O}$ inquérito no Parque Indígena do Xingu atendeu a reivindicações da própria população indígena, preocupada com o aumento de casos de DST nas aldeias e com o surgimento de dois casos de câncer do colo uterino em anos anteriores ao presente estudo.

Durante as visitas às aldeias, verificou-se elevada ocorrência de vaginite e cervicite, sendo indicado o tratamento imediato quando a etiologia era clinicamente evidente. A impressão subjetiva de alta prevalência de infecções cérvico-vaginais foi amplamente confirmada pelos resultados citológicos. Constatou-se que somente $12 \%$ das mulheres apresentavam flora vaginal normal, sendo de $84 \%$ a prevalência de atipias celulares inflamatórias. Foi especialmente importante o achado de infecções por HPV em $2 \%$ das mulheres. Está bem estabelecida, atualmente, a relação causa-efeito entre as infecções pelo HPV e o desenvolvimento de neoplasia epitelial do trato genital feminino e masculino $(10,12)$. Mais de 70 tipos de HPV estão identificados e numerados. Entre estes, os tipos 16 e 18, principalmente, estão implicados no desenvolvimento de neoplasia cervical (13). Embora o condiloma acuminado seja a expressão clínica mais freqüente 
no PIX (sendo causado pelos tipos 6 ou 11), admite-se que o HPV tipo 16 possa ser identificado em até $10 \%$ destas mulheres (15). A melhor forma de identificar o agente etiológico nas infecções vaginais é através do exame a fresco, direto, do conteúdo vaginal. No presente estudo, somente em alguns esfregaços foi possível identificar Trichomonas vaginalis ou achados sugestivos de vaginose bacteriana, já que as lâminas foram fixadas com solução éter-álcool. Além disso, nesse estudo não foi possível identificar os tipos de $\mathrm{HPV}$, já que não foi realizada a hibridização molecular do material nos casos de biópsia devido ao alto custo do procedimento. A presença de infecção por HPV foi quantificada através do achado de coilocitose nos esfregaços cérvico-vaginais.

Outro aspecto relevante diz respeito aos parceiros sexuais das mulheres portadoras de HPV. Além do risco individual de neoplasia intra-epitelial peniana (20), tais parceiros constituem fonte de infecção para outras mulheres e, conseqüentemente, concorrem para a propagação do vírus na população indígena. Devem fazer parte das medidas preventivas a promoção do uso de preservativo, o tratamento dos casos sintomáticos, a detecção e o tratamento das infecções assintomáticas e a investigação dos contatos sexuais de homens e mulheres infectadas. Os resultados encontrados permitem antever que a história natural do câncer de colo uterino seguirá o seu curso biológico no PIX, caso não seja criado um programa sistemático de intervenção diagnóstica e terapêutica.

O desafio que se apresenta no PIX é o de tentar reduzir a incidência das DST, assim como do carcinoma do colo uterino, sem interferir radicalmente nos hábitos socioculturais das comunidades indígenas. A conscientização das lideranças locais para o problema e o treinamento específico de agentes indígenas de saúde para a coleta de citologia cérvico-vaginal e para o diagnóstico e tratamento das DST são indispensáveis para assegurar a continuidade de um programa de prevenção do câncer do colo uterino. Tal programa deve incluir a assistência ginecológica nas aldeias, com coleta pe- riódica de citologia cérvico-vaginal, complementada por colposcopia e estudo histológico nos casos de displasia. Atualmente, as mulheres que apresentam vaginite de repetição no PIX são examinadas nos postos de saúde permanentes, onde a citologia é colhida por enfermeira treinada. A repetição do inquérito de campo ocorre a cada 5 anos. A grande dificuldade tem sido estabelecer a referência com centros especializados para os casos indicados, uma vez que a maioria dos povos indígenas do país habita a Amazônia, onde a oferta de serviços de saúde à população é precária, mesmo nas áreas urbanas.

Agradecimentos. Este trabalho tornou-se possível graças ao apoio da Fundação Nacional do Índio (FUNAI), das lideranças indígenas e dos agentes indígenas de saúde do Parque Indígena do Xingu. Os agradecimentos se estendem à enfermeira Marina Machado, pela colaboração no trabalho de campo, e a todas as mulheres índias incluídas no presente estudo.

\section{REFERÊNCIAS}

1. Brumini R. Câncer no Brasil: dados histopatológicos, 1976/1980. Rio de Janeiro: Comissão Nacional do Controle do Câncer/Ministério da Saúde; 1982.

2. Mendonça GAS. Câncer na população feminina brasileira. Rev Saude Publica 1993;27 (1):68-75.

3. Lazcano $P$, Hernández A, López $C$, Alonso de Ruiz P, Torres L, Gonzales L, et al. Factores de riesgo reproductivo e historia de vida sexual asociados a cáncer cervical en México. Rev Invest Clin 1995;47(5):377-385.

4. Brasil, Ministério da Saúde. Controle do câncer cérvico-uterino e de mama. 2a ed. Brasília: Centro de Documentação, Ministério da Saúde; 1989

5. Norsted TL, White E. Cancer incidence among Native Americans of Western Washington. Int J Epidemiol 1989;18(1):22-27.

6. Restrepo HE, González J, Roberts E, Litvak J. Epidemiologia y control del cáncer del cuello uterino en América Latina y el Caribe. Bol Oficin Sanit Panam 1987;102(6):578-593.

7. Young KT, Choi NW. Cancer risk among residents of Manitoba Indian Reserves, 19701979. Can Med Assoc J 1985;132(11):1269-1273.
8. Young KT, Frank JW. Cancer surveillance in a remote Indian population in northwestern Ontario. Am J Public Health 1983;73(5):515-520.

9. Crum CP, Ikenberg H, Richart LM, Gissman L. Human papillomavirus type 16 and early cervical neoplasia. N Eng J Med 1984;310 (14):880-884.

10. Koutsky LA, Holmes KK, Critchlow CW, Stevens CE, Paavonen J, Beckmann AM, et al. A cohort study of the risk of cervical intraepithelial neoplasia grade 2 or 3 in relation to papillomavirus infection. N Engl J Med 1992; 327(18):1272-1278.

11. Lorincz AT, Temple GF, Kurman RJ, Jenson $A B$, Lancaster WD. Oncogenic association of specific human papillomavirus types with cervical neoplasia. J Nat Can Inst 1987;79(4): 671-677.

12. McCance DJ, Singer A. The importance of HPV infections in the male and female genital tract and their relationship to cervical neoplasia. Em: Peto R, Hausen H, eds. Viral etiology of cervical cancer. New York: Cold Spring Harbor; 1986. pp. 312-320.

13. Reeves W, Brinton LA, García M, Brenes MM, Herrero R, Gaitán E, et al. Human Papillo- mavirus infection and cervical cancer in Latin America. N Eng J Med 1989;320(22):1437-1441.

14. Tase TT, Okagaki T, Clark BA, Manias DA, Ostrow RS, Twiggs LB, et al. Human papillomavirus types and localization in adenocarcinoma and adenosquamous carcinoma of the uterine cervix: A study by in-situ DNA hybridization. Cancer Res 1988;48(4):993-998.

15. Storm HH, Nielsen NH, Prener A, Jensen OM. A comparison of cancer in Greenland and Denmark: a study based on routinely collected incidence data 1973-1985, using the Danish population as baseline. Em: Proceedings of the 8th International Congress on Circumpolar Health. Whitehorse, Yukon: University of Manitoba Press; 1990. pp. 470-471.

16. Brito EB, Menezes RC, Martins SJ, Bastos MG, Sousa A. Estudo preliminar para deteç̧ão de cérvico-vaginites e lesões precursoras do câncer de colo uterino em índias da tribo Parakanã. Rev Assoc Med Bras 1996;42(1): 11-15.

17. Papanicolaou GN, Trant HF. The diagnostic value of vaginal smears in carcinoma of the uterus-1941 [classical article]. Arch Pathol Lab Med 1997;121(3):211-224. 
18. Herrero R, Brinton L, Reeves W, Brenes MM, de Britton RC, Gaitán E, et al. Screening for cervical cancer in Latin America: A case-control study. Int J Epidemiol 1992;21(6):1050-1056.

19. Uchimura NS, Martins NV, Focchi S, Baracat EC, Novo NF, Juliano Y, et al. Estudo clínico e colposcópico da cérvice uterina de mulheres das áreas urbana e rural. Rev Bras Ginecol Obstet 1994;16(5):170-174.

20. Barasso R, De Brux J, Croissant O, Orth G. High prevalence of papillomavirus associated with penile intraepithelial neoplasia in sexual partners of women with cervical intraepithelial neoplasia. N Engl J Med 1987;317(15):916-923.
Manuscrito recebido em 15 de outubro de 1998. Aceito em versão revisada em 29 de junho de 1999.

ABSTRACT Although the literature presents worrisome data regarding the incidence of cervical cancer among indigenous populations, in Brazil there is very little information regarding the occurrence of this type of cancer among indigenous peoples. Therefore, the objective of the present descriptive study was to assess the prevalence of cervical cancer and of cervical and vaginal infections among 423 indigenous women living in the Xingu Indian Reservation, in the state of Mato Grosso, Brazil. These women were or had been sexually active. Data were collected between 1989 and 1996. Clinical and gynecological examinations were carried out prior to the collection of cervical specimens and to the performance of cytologic analyses. Upon detection of abnormalities, a colposcopy and a biopsy were also performed. Our results show that $1 \%$ of the women studied presented invasive carcinoma and that $3 \%$ presented premalignant lesions. In addition, 84\% presented inflammatory atypia, resulting from sexually transmitted genital infections. The present findings are in accordance with the results of other international reports regarding the high prevalence of cervical conditions among indigenous populations, and they underscore the need to extend to the indigenous peoples of Brazil programs aiming at the control of sexually transmitted diseases and at the early detection and treatment of cervical cancer. 